\title{
Coupling Characteristics of Permeability and Volume Strain of Sandstone under Seepage-Stress Coupling
}

\author{
Li-jie Long, ${ }^{1 *}$, Dong-yan Liu ${ }^{3}$, Yan Xiang ${ }^{4}$, Hao Zhang ${ }^{5}$ and Shi-hui Liu ${ }^{6}$ \\ ${ }^{1}$ School of Civil Engineering, Chongqing University, Chongqing 400044, China \\ ${ }^{2}$ School of Civil Engineering, Chongqing University of Arts and Sciences, Chongqing 402160, China \\ ${ }^{3}$ School of Civil Engineering and Architecture, Chongqing University of Science and Technology, Chongqing 401331, China \\ ${ }^{4}$ Housing and Urban-Rural Development Bureau of Jintang County, Chengdu 610499, China \\ ${ }^{5}$ The United Front work department of CPC of Nan'an District, Chongqing 400000, China \\ ${ }^{6}$ Department of Civil and Environmental Engineering, Jackson State University, Jackson MS 39217, United States
}

Received 13 June 2020; Accepted 1 August 2020

\begin{abstract}
Rock mass in deep rock engineering exists in the occurrence environment of high stress and water pressure, and its deformation and damage are affected by the coupling action of seepage and stress. An empirical formula calculation model was evolved by permeability, and volume strain was proposed to reveal the coupling relationship between permeability and volume strain of sandstone under seepage-stress coupling action. The law of seepage-stress coupling characteristics through laboratory tests was established. The permeability, volume strain, maximum compaction place, minimum permeability, and volume strain-permeability curves were analyzed on the basis of the steady-state seepage method and volume strain principle. Results demonstrate that: (1) the pore water pressure has a great influence on the permeability in the initial compaction stage, and it is inversely proportional to the initial permeability of rock samples. (2) The volume strain increases with the increase in confining pressure. When the expansion deformation is prolonged, the inflection point from the volume compression stage transfers late to the expansion stage. (3) The percentage of expansion starting point lags behind with the increase in confining pressure. The volume strain at the expansion increases with the increase in confining pressure, while the permeability at the expansion first increases and then decreases. (4) The permeability at the maximum compaction is not the minimum permeability; however, the minimum permeability appears before the inflection point of the volume strain-deviatoric stress curve. The proposed method provides a reference for evaluating the permeability and stability of rock mass under complex stress conditions.
\end{abstract}

Keywords: seepage-stress coupling, sandstone permeability, volume strain of sandstone, coupling characteristics

\section{Introduction}

In the geological environment of deep rock mass, such as hydropower engineering, petroleum engineering, and underground nuclear waste disposal engineering, the rock often exists in a certain groundwater level. The physical and mechanical properties of rock mass change under the action of the water environment. Stress and pore water pressure interact with and restrict each other, thereby forming a seepage-stress coupling effect. Relevant experimental studies and mathematical models have emerged with the increase in the number of engineering issues in terms of seepage-stress coupling. Most studies have discussed the qualitative and quantitative influence of in-situ stress and effective stress on permeability and analyzed the porosity and permeability of sandstone and the effective lateral pressure it can bear [1,2].

However, the pores and fissures in the rock structure are developing towards mesostructural anisotropy and inhomogeneity with the development of deep rock mass engineering; thus, the seepage-stress coupling characteristics of rock are increasingly difficult to accurately describe. The closing and opening of cracks in rock mass

*E-mail address: longli1017@126.com

ISSN: 1791-2377 @ 2020 School of Science, IHU. All rights reserved. doi:10.25103/jestr.134.14 lead to the compaction and expansion of rock volume and the change of permeability. The variation law and functional relationship between volume strain and permeability are introduced. The coupling process of volume strain and permeability is complex, in addition to many parameters and great technical difficulty, thereby bringing great challenges to the study of seepage-stress coupling.

Scholars have conducted a number of studies on permeability and volume strain laws of various types of rock samples under seepage-stress coupling action on the basis of the above analysis $[3,4]$. However, a deviation from the actual state remains in the calculation model and mutual coupling relationship of the evolution law of volume strain and permeability. Therefore, how to accurately describe the changing rules of various mechanical indexes in the coupling process and clarify the coupling characteristics of permeability and volume strain of sandstone under seepagestress coupling must be solved.

Laboratory tests were carried out in terms of permeability and volume strain of sandstone under osmotic pressure-stress coupling by steady seepage method and volume strain principle. The volume strain, permeability, expansion starting point percentage, maximum volume strain, and minimum permeability of sandstone were analyzed. The empirical formulas of permeability and volume strain were established. This study aims to further reflect the evolution law of coupling characteristics of permeability and volume 
strain and then provide reference for the evaluation of rock engineering safety and the prevention and study of geological disasters.

\section{State of the art}

At present, scholars have conducted a number of studies on permeability and volume strain of rock. Chen [5] carried out an experimental study on the permeability characteristics of sandstone at different temperatures and pore water pressures. The author also pointed out that permeability is closely related to axial stress and radial deformation but drew no conclusion on the law of permeability and volume strain. Huo [6] studied the volume strain characteristics of coal and rock mass under the variations of mining-induced stress and established the mathematical model of volume strain and permeability; however, this evolution law is not suitable for other rock masses. Zhang [7] carried out a stress-seepage coupling test of sandstone under drainage condition, and the stress-strain and permeability evolution curves during sandstone deformation were obtained. Accordingly, the mechanical behavior and permeability evolution response curves during sandstone deformation were efficiently characterized. He qualitatively discussed the corresponding relationship between sandstone volume deformation and permeability development. However, he did not quantitatively specify the changing rules of the aforementioned factors. Zhang [8] established a rock strain softening and permeability evolution model considering confining pressure on the basis of the triaxial test results of Gebdykes dolomite, which can efficiently simulate permeability evolution and volume expansion. However, the relationship between volume strain and permeability of mudstone was mainly verified, and the characteristics of their same trend were quite different from those of sandstone. Chen [9] conducted triaxial compression tests on sandstone under different confining pressures and pore pressure differences. The aforementioned author also explored the damage evolution law of sandstone mechanical properties and permeability and discussed the relationship between permeability evolution and volume strain. However, he also pointed out that the evolution of permeability and volume strain cannot be completely clarified due to the inaccurate measurement of radial strain index. An accurate measurement method of volume strain is required to describe this concept in the future. Wang [10] studied the relationship between permeability and volume strain of sandstone in deformation and breaking. The experimental results indicated that the axial, radial, and volume strains of sandstone have obvious laws with permeability. The experimental data indicated that the empirical equation of permeability and volume strain was obtained by fitting the regular curve. However, the test under constant confining pressure and pore water pressure did not discuss the influence of the change of confining pressure and pore water pressure on volume strain and permeability. $\mathrm{Wu}$ [11] deduced the failure function model related to volume strain and proposed the elastoplastic damage evolution model and differential elastoplastic constitutive equation relative to volume strain in the analysis. The conclusion was mainly proved by engineering practice but lacked of laboratory data. Harpalani [12] discussed the linear relationship between the permeability of coalbed methane and the volumetric strain of coal matrix desorbed by gas. The author found that the change of permeability related to matrix shrinkage can be estimated from the adsorption isotherm of coal. However, constant value $\alpha$ must be estimated in advance, but further tests would be conducted to determine the different types of constant $\alpha$ values. Renard [13] obtained a microresolution fault map in triaxial compression loading of sandstone by using X-ray microfault imaging technology and carried out digital volume correlation analysis on it. The expansion and shear strain of sandstone were observed at microscale and macroscale before the failure, thereby providing a new quantitative method for the test results of rock. However, an analysis on permeability is still lacking. Jamie [14] studied that the increase of load on the brittle deformed volcanic rock samples with low porosity during lava extrusion advanced the permeability between the conduit and the fault. The author further revealed the evolution of fault permeability with the increase in inelastic strain, without involving the influence of volume strain in this process. Wei et al. [15] studied the internal structure of rock and the expansion caused by the action of liquid. The tiny particles carried in the liquid would block some narrow flow channels. However, the aforementioned authors did not analyze the volume strain after expansion in detail. Jorden [16] focused on the volume strain and mass loss in the critical weathering zone of rocks and proved that the volume strain can not be ignored in the pore formation mechanism of saprophytic rocks. However, the author did not demonstrate the relationship between volume strain and pore water. Kim [17] investigated the crack initiation and damage stress threshold of tunnel granite with the acoustic emission device and deduced the damage parameters by using the volume strain of crack. However, the permeability change caused by crack development was not discussed in this study. Shalev [18] explained that the wellhead water level was affected by the coupling response of volume strain and offset strain and quantitatively analyzed the coupling parameters. However, the author did not discuss the fluid-structure coupling problem of rocks with damaged fractures. Nermoen [19] proved that the interaction between chemical fluid and rock resulted in volume strain, porosity and permeability changes, and other mechanical and chemical effects by observing the complete chemical changes in the Cretaceous core. The permeability-porosity model was proposed to explore a new method for analyzing the compaction degree and fluid core scale, while the change of volume strain will be further explored.

The above-mentioned studies mainly focus on permeability or volume strain for experimental and theoretical analysis. The study on the coupling characteristics of permeability and volume strain of sandstone is relatively rare, especially on the relationship between volume strain and permeability at volume expansion and the analysis on the appearance rule of maximum volume strain and minimum permeability in the relationship curve between volume strain and permeability. In this study, the steady-state seepage method was used for the seepage test of sandstone under seepage-stress coupling. The stress-strain curve, the influence curve of permeability, and the volume strain of sandstone under seepage-stress coupling was obtained. The characteristics of permeability at the volume expansion point, volume strain at the expansion point, percentage of expansion starting point, maximum volume strain, and minimum permeability were discussed on the basis of the principle of volume strain. The empirical formula of permeability and volumetric strain evolution under seepage-stress coupling was established, thereby 
providing experimental basis for solving similar engineering problems and subsequent study.

The remainder of this study is organized as follows. Section 3 describes the experimental principle, test instruments, sample preparation, and test methods. Section 4 discusses the coupling characteristics of permeability and volume strain by analyzing the test data and various characteristic indexes. This section also constructs the empirical formula under the seepage-stress coupling action. Section 5 summarizes the conclusions.

\section{Methodology}

\subsection{Test principle}

The following are the two main methods used to test the permeability of the rock samples: steady seepage and transient pressure pulse methods. In this test, the steady-state method is mainly used. During stress loading, the tester automatically records the stress-strain curve of rock, and the pressure pump stroke of the hydraulic system simultaneously records the volume of water flowing into the rock sample. The permeability of the rock sample at each moment can be obtained by calculating the relationship between the flow rates flowing into the rock sample and time. The calculation formula of permeability $k\left(\mathrm{~m}^{2}\right)$ is as follows assuming that the seepage conforms to Darcy's law:

$$
k=\frac{Q \mu L}{\Delta P A}
$$

Wherein, $Q$ is the flow rate of water through the crosssectional area of rock sample per unit time $\left(\mathrm{m}^{3} / \mathrm{s}\right), \quad L$ is the sample length $(m), \quad \mu$ is the viscosity of the fluid(water at normal temperature $\left.=1.005 \times 10^{-3} \mathrm{~Pa} \cdot s\right), A$ is the crosssectional area of rock sample $\left(\mathrm{m}^{2}\right), d$ is the diameter of rock sample $\left(\mathrm{m}^{2}\right), \Delta P$ is the pressure difference at both ends of the rock sample $(\mathrm{Pa})$.

\subsection{Testers}

This test was completed on TRIAXIAL CELL V4.0 "Rock Multi-field Coupling Triaxial Instrument" test system introduced by School of Civil Engineering, Chongqing University, which was studied and developed by Lille University of Technology, France. The test system is shown in Figure 1. The system consists of automatic servo devices for confining, axial, and pore fluid pressures and is suitable for multifield coupling experiments, such as temperaturefluid-mechanics-chemistry coupling of rock geological materials. The main technical parameters are as follows: Maximum axial pressure: $1000 k N$, maximum confining pressure: $60 \mathrm{MPa}$, maximum axial eccentric stress: $375 \mathrm{MPa}$, maximum pore pressure: $60 \mathrm{MPa}$ and test temperature range: room temperature $-90{ }^{\circ} \mathrm{C}$. The system can realize the simultaneous loading of temperature, confining pressure, and pore water pressure and automatically record the values of load, stress, displacement, and fluid pressure. This study can also simultaneously draw the real-time measurement and control values into mechanical curves to express them.

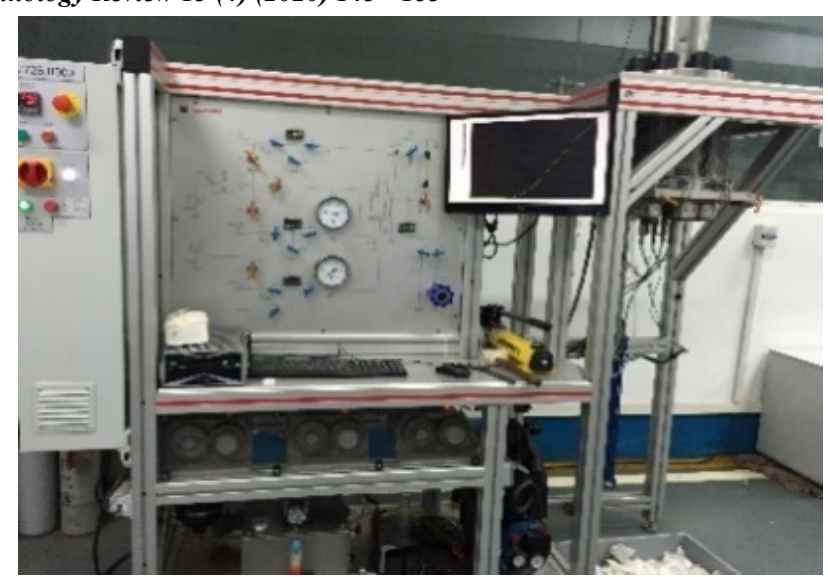

Fig. 1. Rock multi-field coupling triaxial apparatus

\subsection{Preparation of the test rock sample}

The sandstone used in this test was taken from a mining area in Beibei District, Chongqing, with an average density of $2374 \mathrm{~kg} / \mathrm{m}^{3}$. Standard rock specimens with a size of $50 \mathrm{~mm} \times 100 \mathrm{~mm}$ were prepared according to the requirements of the Standard of Engineering Rock Mass Test Method and the Code of Rock Test for Water Resources and Hydropower Engineering (Figure 2). Three groups of samples were prepared in succession, with three samples in each group, thereby totaling 27 samples. These groups were used for permeability tests at different confining and pore water pressures. X-ray diffraction composition analysis was carried out by randomly selecting sandstone samples (Figure 3).

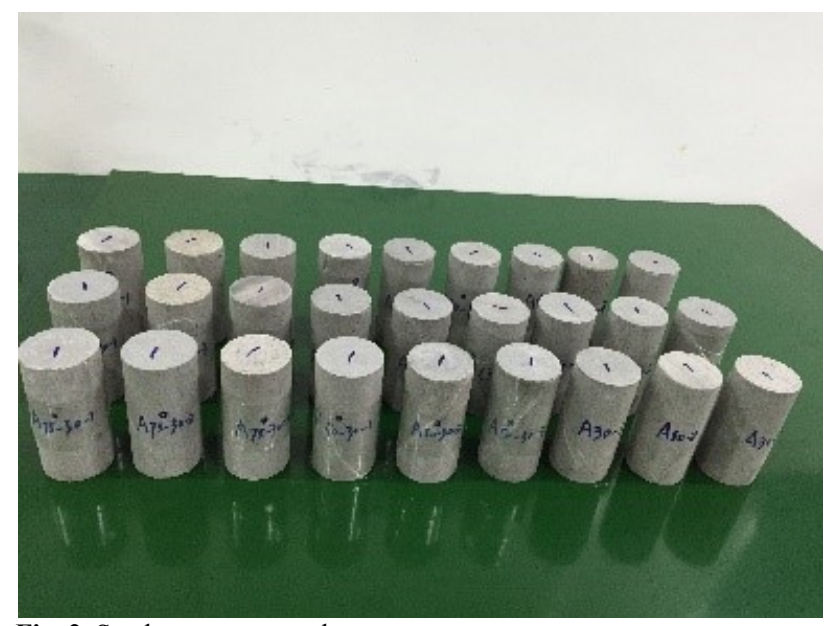

Fig. 2. Sandstone test sample

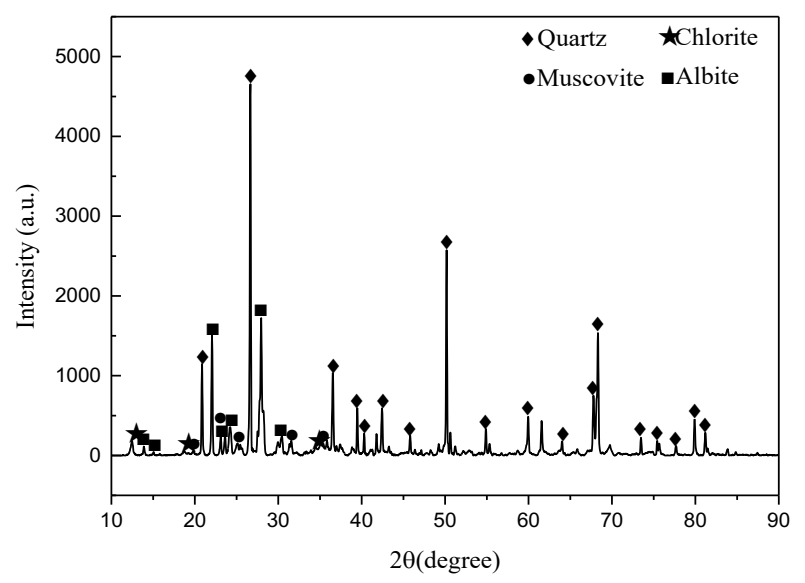

Fig. 3. XRD diffraction analysis of sandstone composition 


\subsection{Test method}

In this study, 10, 20, and $30 M P a$ confining pressures and 2, 5, and $8 \mathrm{MPa}$ pore water pressures were selected for analysis. The specific experimental steps are as follows:

(1) At first, the processed sandstone samples were continuously baked in an oven at $105^{\circ} \mathrm{C}$ for $24 \mathrm{~h}$. After the samples were cooled for $24 h$, they were placed into the SRH intelligent concrete vacuum water saturator produced by Beijing Shourui Company for saturation. The samples were continuously pumped at a pressure of $-90 \mathrm{kPa}$ for $4 \mathrm{~h}$ and soaked in distilled water for more than $48 h$ to ensure that the samples are maintained in a saturated single-phase flow state.

(2) The saturated sandstone sample was packed in a special fluorine rubber sleeve matched with the instrument and tightly wrapped for oil insulation. The standard saturated sample was packed into the instrument, the upper and lower permeable gaskets were installed according to the test regulations, and the only sensor and strain measuring device were connected. The axial strain was measured by a twobranch linear displacement sensor. The circumferential strain was measured by a circumferential electronic strain gauge at the center of the sample. The pointer position was adjusted, the drain pipe and hoop were screwed, and the pressure chamber was installed into it.

(3) An axial displacement control mode was adopted. Confining pressure was first applied to a predetermined value. The valve was then opened to apply pore water pressure to a predetermined value after the confining pressure was stable. The seepage situation at the outlet was observed after the osmotic pressure has fully penetrated inside the sandstone specimen. This study ensured that the specimen has fully penetrated when stable water drops were formed at the outlet end.

(4) After the sample was fully infiltrated, the upper limit of displacement was set to $10 \mathrm{~mm}$, and the axial load was applied at a loading rate of $0.01 \mathrm{~mm} / \mathrm{min}$ until the rock sample was destroyed. During this process, the tester automatically recorded the stress-strain curve of the rock.

(5) The data collection was ended after the specimen was destroyed. The axial pressure was unloaded, followed by the confining pressure. The test pieces were taken out, and the data were sorted. The volume of water flowing into the sample in a certain period of time can be calculated according to the pressure stroke of the water pump. The flow rate of water flowing into the $P 3$ pump in a certain period of time can be determined. The permeability value of rock in a certain period of time can be calculated by substituting Formula (1).

\section{Analysis and discussion}

\subsection{Influence of pore water and confining pressures on permeability}

\subsubsection{Influence of pore water pressure on permeability}

During rock compression, rock has experienced four stages in the stress-strain test: compaction, elasticity, yield, and breakage. The generation and development of cracks in rock are closely related to rock permeability. The test results indicated that the relationship curves of permeability, deviatoric stress, and axial strain under different pore water pressures with constant confining pressure were formed. Figure 5 shows that the influence of pore water pressure on permeability was studied with the confining pressure of 10 $M P a$ as an example.

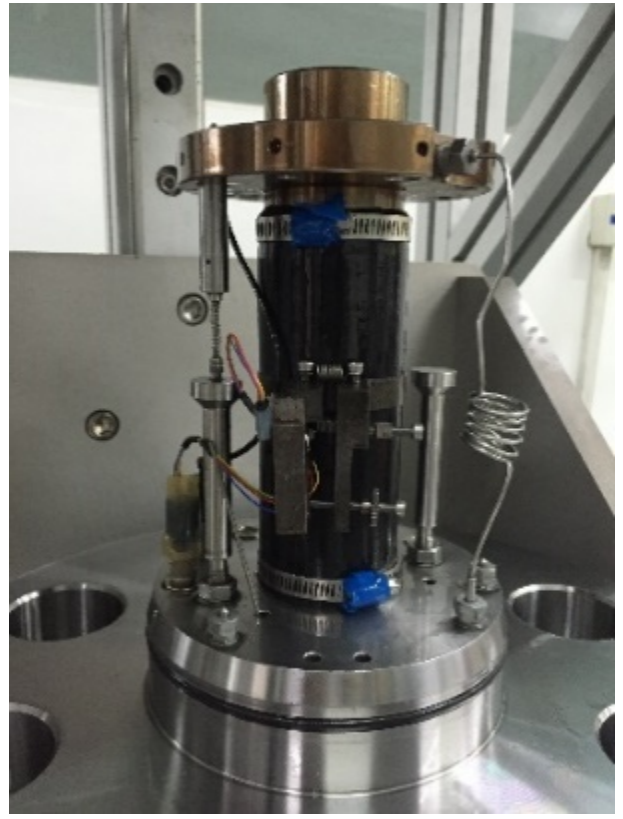

Fig. 4. Sample assembly drawing

In the initial loading stage, the initial permeabilities of the rock samples are $17.242 \times 10^{-18}, 25.081 \times 10^{-18}$, and $28.482 \times 10^{-18}$ when the pore water pressures are 2,5 , and 8 $M P a$, respectively. The permeability of rock samples under $8 \mathrm{MPa}$ pore water pressure is 1.65 times that under $2 \mathrm{MPa}$. Meanwhile, the permeability under $8 \mathrm{MPa}$ is 1.14 times that under $5 \mathrm{MPa}$. The initial permeability of the rock sample is related to pore water pressure, and it reduces the stress intensity factor at the tip of microcrack in rock. When the permeability decreases to the critical stress, the crack expands and penetrates. The wedging action of pore water pressure also weakens the cementation ability between particles, softens the mineral components in rocks, intensifies crack propagation, and improves the permeability of rocks. Few channels of seepage are formed in the internal cracks of rock, and the initial permeability is low when the pore water pressure is low. The initial permeability of the rock sample is high when the pore water pressure is also high.

The axial strain of the rock sample continued to increase with the increase in axial load. When the axial strain reached $0.17 \%$, the cracks in the rock sample were in the maximum compression state under the action of axial eccentric stress. The permeability values of each pore under water pressure successively reached the minimum values, which were $7.749 \times 10^{-18}, 20.977 \times 10^{-18}$, and $25.307 \times 10^{-18}$. When the axial eccentric stress continued to increase, the rock sample entered the yield stage. The crack reaching the maximum compression state continued to crack and expand, and the permeability steadily increased and showed a rapidly increasing trend. When the stress continued to increase, the volume of the rock sample expanded, and the microcracks further connected and formed macroscopic cracks. The permeability of the rock sample entered the high permeability area. The above tests demonstrated that the permeability of rock is greatly affected by pore water pressure in the initial stage under the stress state of constant confining pressure and different pore water pressures. 


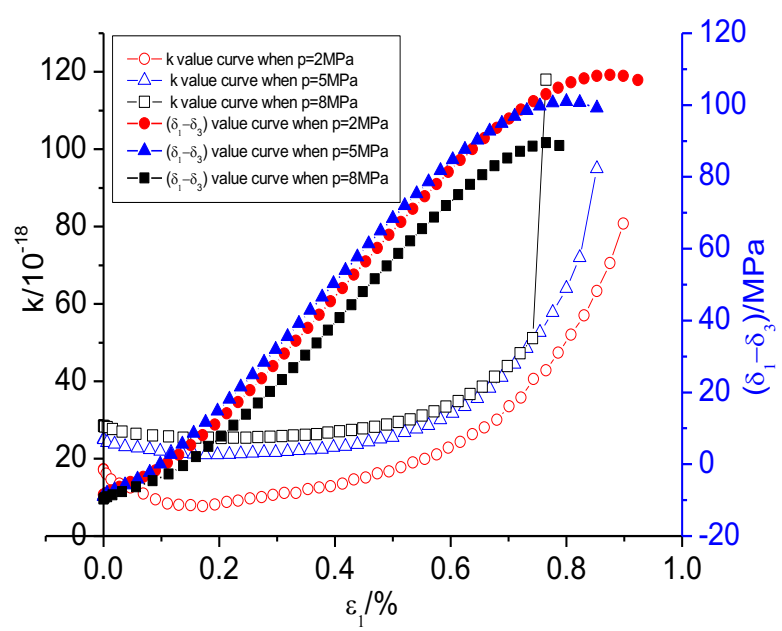

Fig. 5. Relationship between permeability, deviatoric stress and axial strain under different pore water pressures when confining pressure is $10 \mathrm{MPa}$

\subsubsection{Influence of pore water pressure on permeability}

The example of this situation is shown in Figure 6. At the pore water pressure $P=2 M P a$, the initial permeabilities of the rock samples are $17.242 \times 10^{-18}, 33.248 \times 10^{-18}$, and $8.169 \times 10^{-18}$ when the confining pressures are 10,20 , and $30 \mathrm{MPa}$, respectively. However, the internal pores and microcracks of the rock samples are continuously compressed and squeezed during loading with the increase in deviatoric stress. The compaction effect is obvious when the confining pressure is high. The permeability decreases when the internal pores and microcracks are closed. When the permeability curve develops from compression to linear elastic stages, it shows a downward fluctuation and decline trend. When the pore water pressure is constant, the initial permeability gradually decreases with the increase in confining pressure, and the decrease amplitude is within one order of magnitude. When the pore water pressure is $2 \mathrm{MPa}$, and the axial strain is less than $0.17 \%$, the permeability curve decreases with the increase in confining pressure. After entering the elastic stage, the curve of deviatoric stress and axial strain is almost straight, and the permeability steadily increases with the increase in confining pressure. When the confining pressures are 10,20 , and $30 M P a$, the average permeabilities of the rock samples in the online elastic stage are $13.385 \times 10^{-18}, 27.082 \times 10^{-18}$, and $2.479 \times 10^{-18}$, which are $22.37 \%, 18.55 \%$, and $69.66 \%$ lower than the initial permeability, respectively. The comparison result of the initial permeability increment and peak strength reduction value according to Table 1 indicated that when the pore water pressure increases with constant confining pressure, the initial permeability increase is within the same order of magnitude. The stress peak strength decrease is large when the confining pressure is $10 \mathrm{MPa}$ and small when the confining pressure is $30 M P a$, and the decrease value when the confining pressure is $20 \mathrm{MPa}$ is between them. This finding shows that the pore water pressure has a more significant influence on peak strength under low than under high confining pressure.

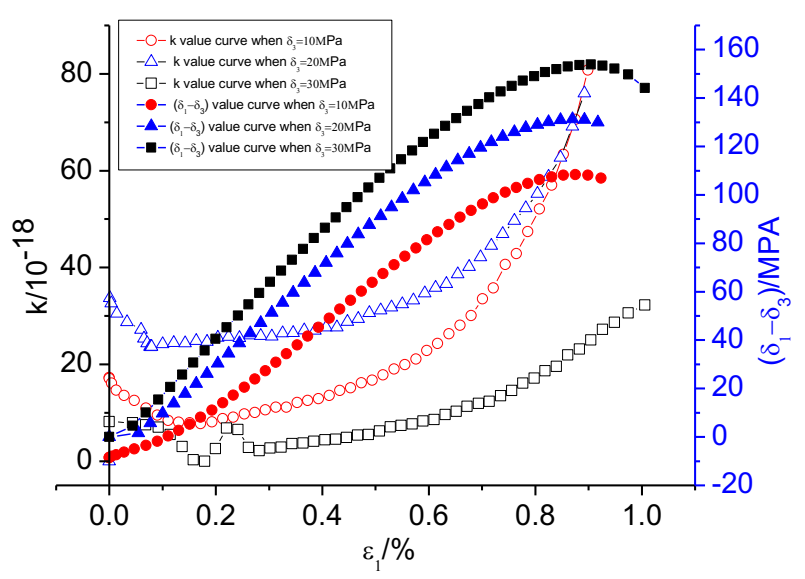

Fig. 6. Relationship between permeability, deviatoric stress and axial strain under different confining pressures when pore water pressure is 2 $\mathrm{MPa}$

Table 1. Table of initial permeability and peak strength under different confining pressures and pore water pressures

\begin{tabular}{c|c|c|c|c}
\hline $\begin{array}{c}\text { Samples/ } \\
M P a\end{array}$ & $\begin{array}{c}\text { Initial } \\
\text { permeability } \\
/ \mathbf{1 0}^{-\mathbf{1 8}} \mathbf{~ m}^{\mathbf{2}}\end{array}$ & $\begin{array}{c}\text { Increment of } \\
\text { initial } \\
\text { permeability } \\
\mathbf{I 0}^{-\mathbf{- 1 8}} \mathbf{~ m}^{\mathbf{2}}\end{array}$ & $\begin{array}{c}\text { Peak } \\
\text { intensity } \\
/ \mathrm{MPa}\end{array}$ & $\begin{array}{c}\text { Peak } \\
\text { reduction } \\
\text { value } \\
/ \mathrm{MPa}\end{array}$ \\
\hline $10-2$ & 17.242 & 11.24 & 118.41 & 18.891 \\
$10-5$ & 25.081 & & 110.941 & \\
$10-8$ & 28.482 & & 99.519 & \\
\hline $20-2$ & 33.245 & -5.768 & 151.256 & 11.88 \\
$20-5$ & 25.487 & & 146.544 & \\
$20-8$ & 27.480 & & 139.376 & \\
\hline $30-2$ & 8.169 & 4.3 & 183.805 & 11.211 \\
$30-5$ & 10.629 & & 179.931 & \\
$30-8$ & 12.469 & & 172.594 & \\
\hline
\end{tabular}

4.2 Influence of pore water pressure and confining pressure on volume strain

\subsubsection{Influence of different confining pressures on volume strain}

The volume strain of rock is the change of unit volume when the rock is stressed. The volume compression of rock sample is a positive value, and the volume expansion is a negative one. Figure 7 shows that the characteristic stress values of sandstone increased to varying degrees with the increase in confining pressure because the pore water pressure was constant. The compression deformation value that the rock can bear before expansion is great, and the expansion deformation and the turning point of the volume strain curve from compression to expansion appeared later when the when confining pressure was high. This finding was consistent with the following theoretical analysis: the increase of confining pressure improved the sealing of pores and fissures in rocks.

\subsubsection{Influence of different osmotic pressures on volume strain}

Figure 8 demonstrates that the variation range of volume strain peak and expansion turning point was small because the confining pressure was constant. In this experiment, the influence of different pore water pressures on the volume strain was insignificant when the confining pressure was constant. This phenomenon was also related to the small variation interval of the pore water pressure, thereby causing slight volume strain. 


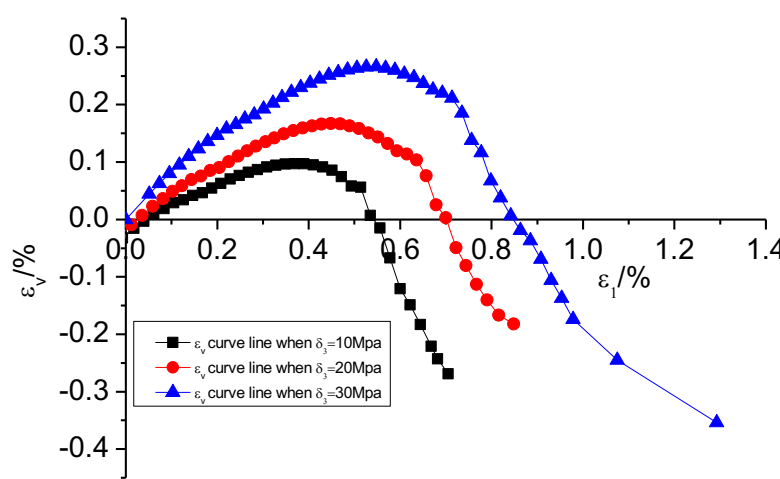

Fig. 7. Volume strain of sandstone under different confining pressures when osmotic pressure is $8 \mathrm{MPa}$

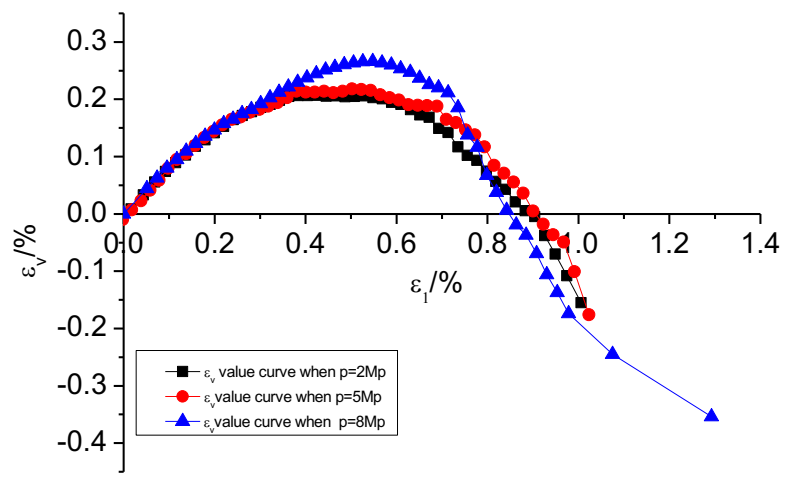

Fig. 8. Volume strain of sandstone under different water pressures when confining pressure is $30 \mathrm{MPa}$

\subsection{Analysis of the coupling characteristics of permeability and volume strain}

4.3.1 Analysis of the law of volume strain and permeability at the volume expansion point

In the relationship curve between volumetric strain and deviatoric stress, Alkan [20] et al. defined that the turning point of the sample volume from compression to expansion in the yield stage was the compression-expansion boundary point, which was the expansion starting point. Before the expansion starting point, the volume of rock was compressed to the minimum under stress, and then the volume expansion increased. The phenomenon of rock expansion was different under varying pore water and confining pressure coupling.

The test results indicated that the axial strain-deviatoric stress and axial strain-volume strain curves of sandstone under various stress states were formed. The rock crack development can be divided into five stages: crack closure stage, elastic stage, crack initiation stage, stable crack propagation stage, and unstable crack propagation stage. The expansion starting point is the sign of entering the stage of stable crack propagation and indicates that the microcracks and cracks in the rock sample begin to stably develop and penetrate. The stress state at the peak stress is as follows: each crack forms and propagates through the main crack and cracks at the relatively weak bond. The eccentric stress at the starting point of expansion is smaller than the peak stress, which is consistent with the test results. Figure 9 shows that the eccentric and peak stresses at the starting point of expansion increased with the increase in confining pressure. The sensitivity of axial strain-volume strain curve to the change of confining pressure was also higher than that of the stress-strain curve. In the surrounding rock engineering bearing long-term compressive strength, properly increasing the confining pressure can improve the long-term compressive strength of rock mass.

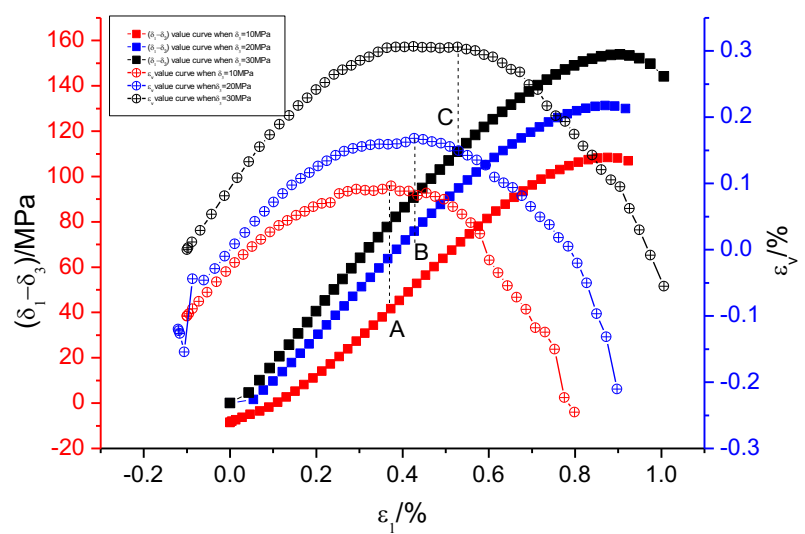

Fig. 9. Axial strain-deviatoric stress and axial strain-volume strain curves under different confining pressures when osmotic pressure is 2 $\mathrm{MPa}$

The analysis of the experimental results indicated that the relationship diagram between confining pressure and expansion starting point percentage was created. The relationship between expansion starting point percentage and confining pressure was obtained (Figure 10) according to the values of volume strain and permeability at expansion starting point under different pore water and confining pressures. When the confining pressures were 10 and $30 M P a$, the percentage of expansion starting point first decreased and then increased with the increase in pore water pressure. When the confining pressure was $20 \mathrm{MPa}$, the expansion starting point was also elevated with the increase in pore water pressure. When the pore water pressures were $P=2$ and $8 \mathrm{MPa}$, the expansion starting point percentage increased with the increase in confining pressure, thereby showing a hysteresis phenomenon. When the pore water pressure was $\mathrm{p}=5 \mathrm{MPa}$, the expansion starting point percentage showed an irregular and advance phenomenon with the increase in confining pressure.

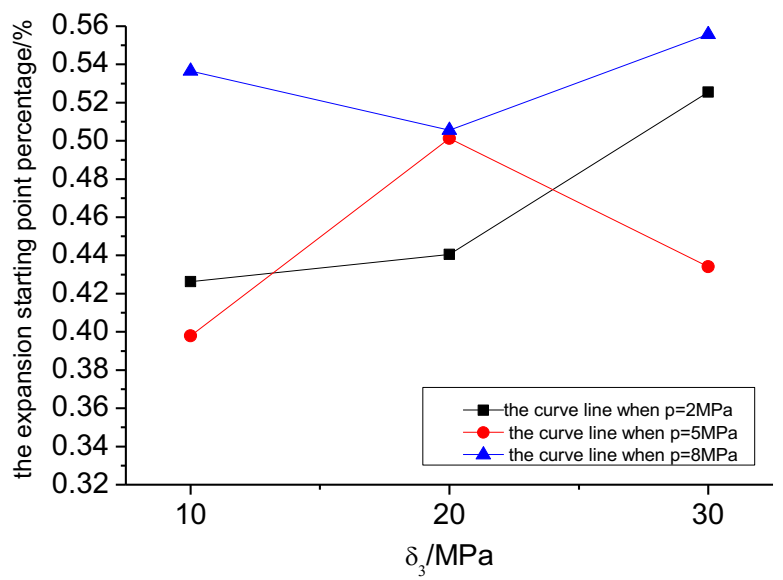

Fig. 10. Relationship between expansion percentage and confining pressure under different pore water pressures

Given that the volume strain at the expansion point of the sample is the turning point of the crack in the rock from gradual opening to permanent damage, it is also called the critical point of damage or the boundary point of compression expansion. After passing this critical point, the unstable cracks in the rock samples rapidly increased, 
Li-jie Long, Dong-yan Liu, Yan Xiang, Hao Zhang and Shi-hui Liu/

Journal of Engineering Science and Technology Review 13 (4) (2020) 143 - 153

thereby leading to the increase in pore volume and permeability; thus, it is also the turning point of permeability from low to high. Figure 11 demonstrates that the volume strain at the expansion area generally showed the characteristics of increasing with the increase in loading confining pressure because the pore water pressure was constant. At pore water pressures of $P=5$ and $8 M P a$, the volume strain at expansion increased with the increase in confining pressure, which is consistent with the increase in stress in the shear direction and the rapid growth rate of axial strain. In this experiment, the volume strain at the confining pressure of $30 \mathrm{MPa}$ decreased when the pore water pressure was $P=2 M P a$, which was related to the fluctuation of rock samples. Figure 12 demonstrates that the permeability at the volume strain expansion of the sample showed the characteristics of first rising and then falling with the increase in confining pressure because the pore water pressure was constant. When the boundary point of volume expansion was exceeded, the permeability of the sample greatly increased.

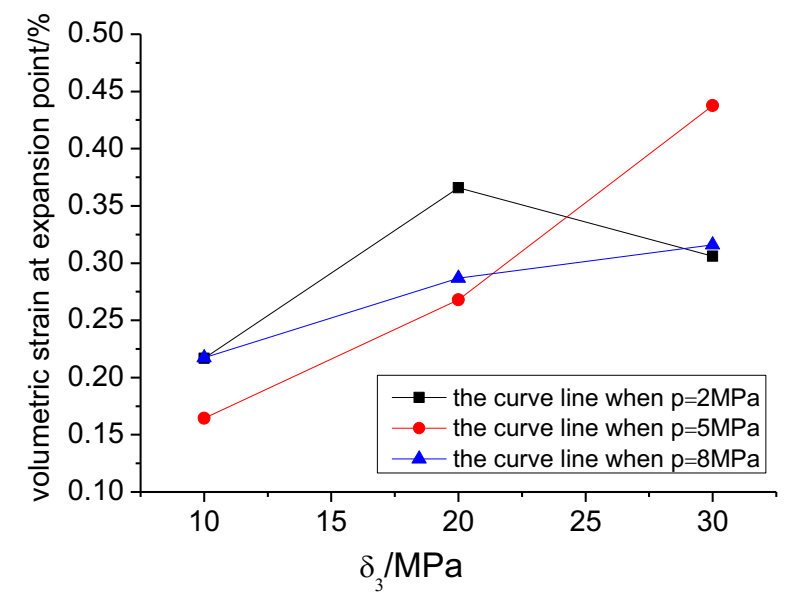

Fig. 11. Relationship between volumetric strain and confining pressure at expansion point under different pore water pressures

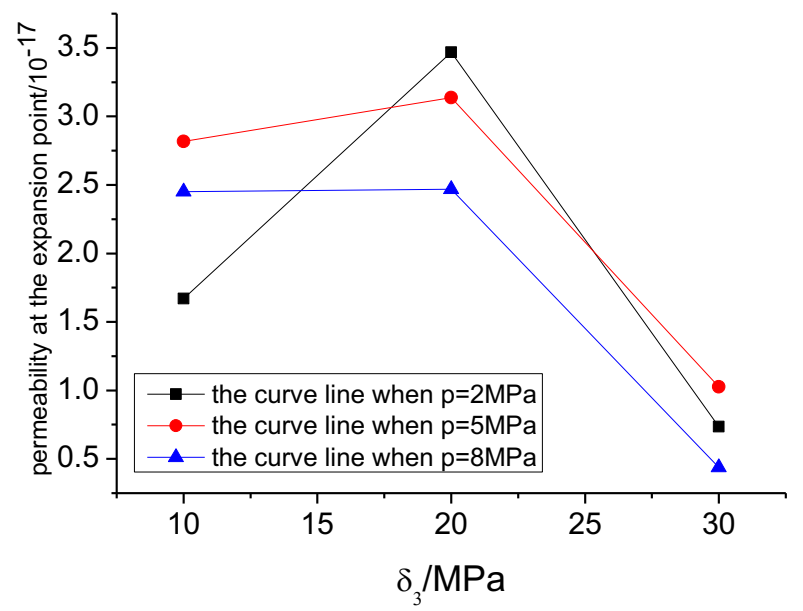

Fig. 12. Relationship between permeability and confining pressure in expansion area under different pore water pressures

\subsubsection{Analysis of volume strain-deviatoric stress and volume strain-permeability curves}

The test data indicated that the volume strain-deviatoric stress and volume strain-permeability curves under different confining and pore water pressures were formed. The coupling law of volume strain with permeability and deviatoric stress under different confining pressures and osmotic pressures was analyzed.

Figure 13 demonstrates that the volume strain of rock samples has undergone two stages: volume compression and volume expansion. When the specimen was subjected to eccentric stress at the beginning of the test, it mainly showed the compaction of primary cracks and the closure of pores. The pore structure was continuously compressed with the increase in stress, and the volume of the specimen was shrunk. At this stage, the eccentric stress continued to increase, and the existing internal damage was compressed and sealed under the action of external stress, thereby further reducing the permeability coefficient of the specimen to the minimum value $k_{\min }$. When the deviatoric stress continued to increase, a large number of microcracks made the lateral strain of the specimen increase more than the vertical positive strain, thereby resulting in rock volume expansion. The internal seepage channel greatly increased, and the permeability showed a rapid growth trend. The pore water pressure intensified the connection of pores and the expansion of cracks in the specimen, thereby further increasing the volume and permeability coefficient of the specimen. The volume strain $\varepsilon_{v}$ of the specimen entered the expansion stage, the volume of the specimen expanded, and the permeability rapidly increased. Table 2 illustrates the maximum volume strain and minimum permeability in the curve.

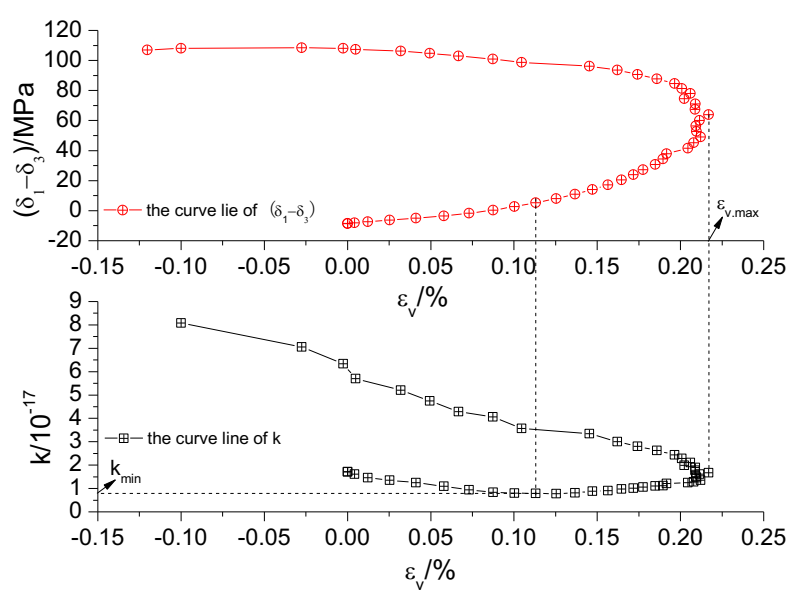

(1) The confining pressure is $10 \mathrm{MPa}$ and pore water pressure is 2 $M P a$

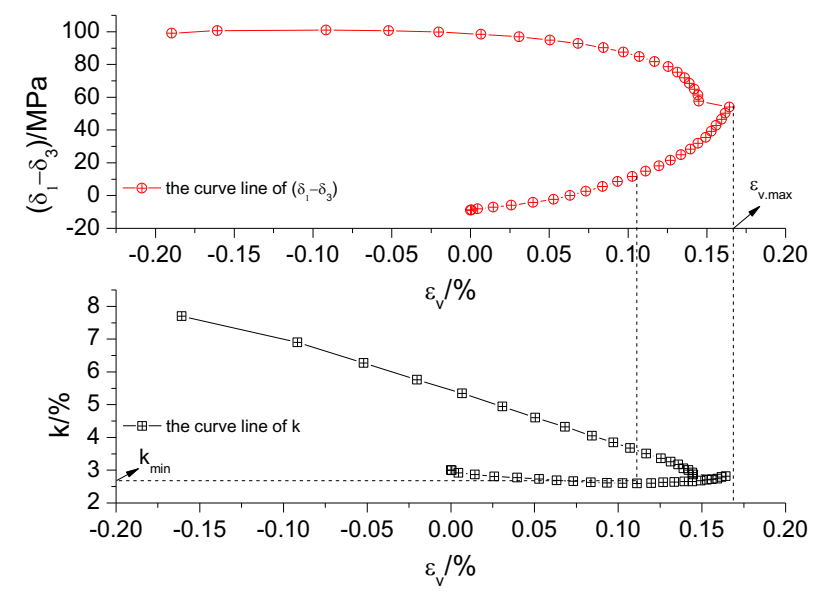

(2) The confining pressure is $10 M P a$ and pore water pressure is $5 \mathrm{MPa}$ 
Li-jie Long, Dong-yan Liu, Yan Xiang, Hao Zhang and Shi-hui Liu/

Journal of Engineering Science and Technology Review 13 (4) (2020) 143 - 153

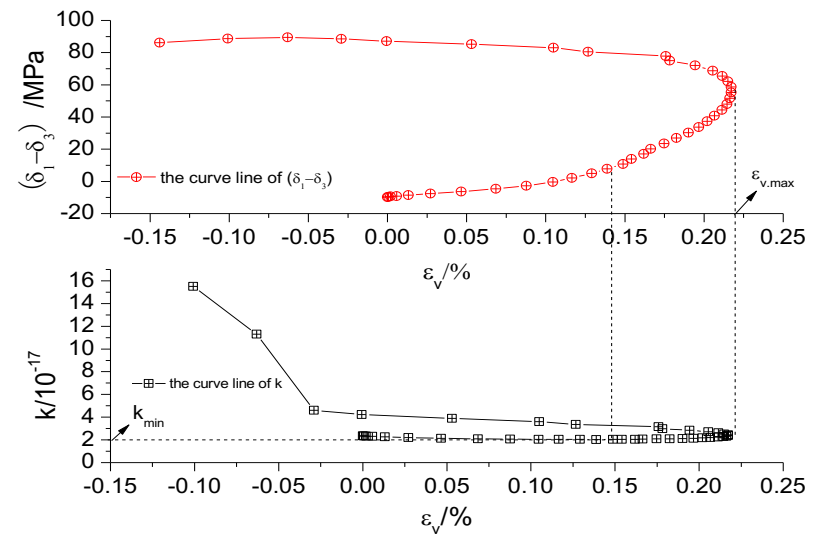

(3) The confining pressure is $10 \mathrm{MPa}$ and pore water pressure is 8 $\mathrm{MPa}$

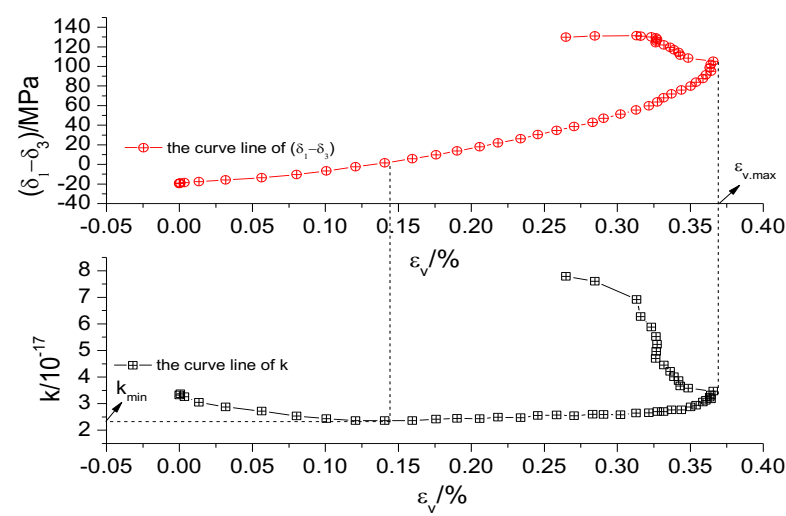

(4) The confining pressure is $20 \mathrm{MPa}$ and pore water pressure is 2 $M P a$

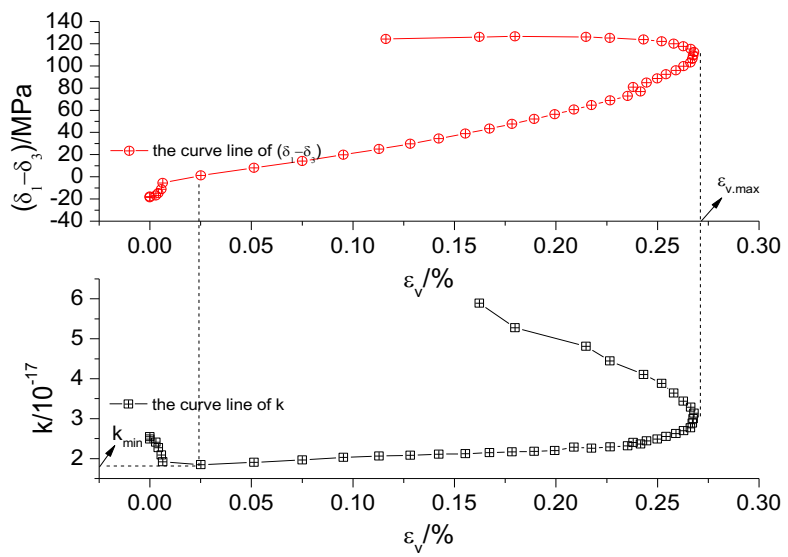

(5) The confining pressure is $20 M P a$ and pore water pressure is $5 \mathrm{MPa}$

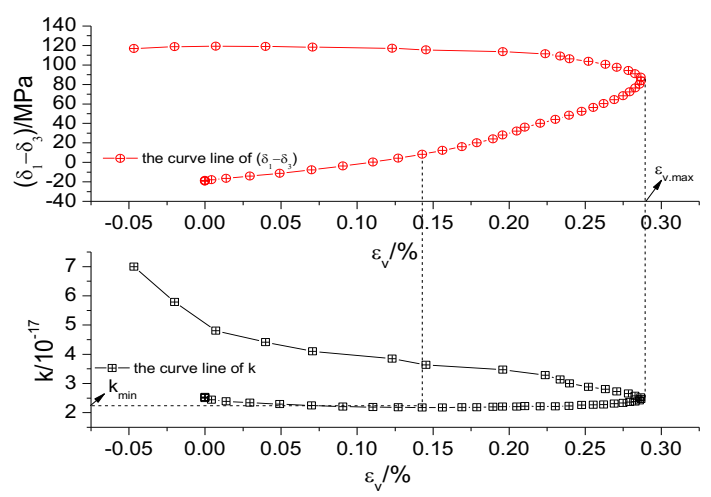

(6) The confining pressure is $20 \mathrm{MPa}$ and pore water pressure is $8 \mathrm{MPa}$

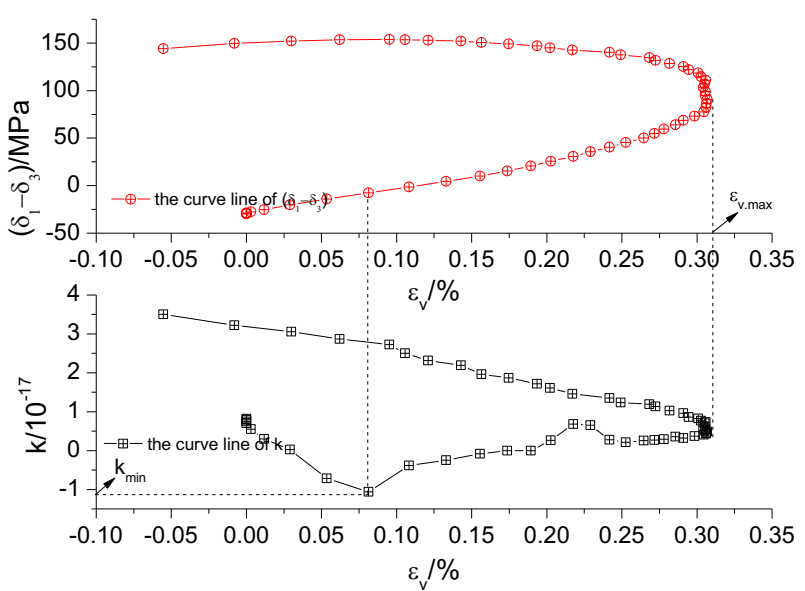

(7) The confining pressure is $30 M P a$ and pore water pressure is $2 \mathrm{MPa}$

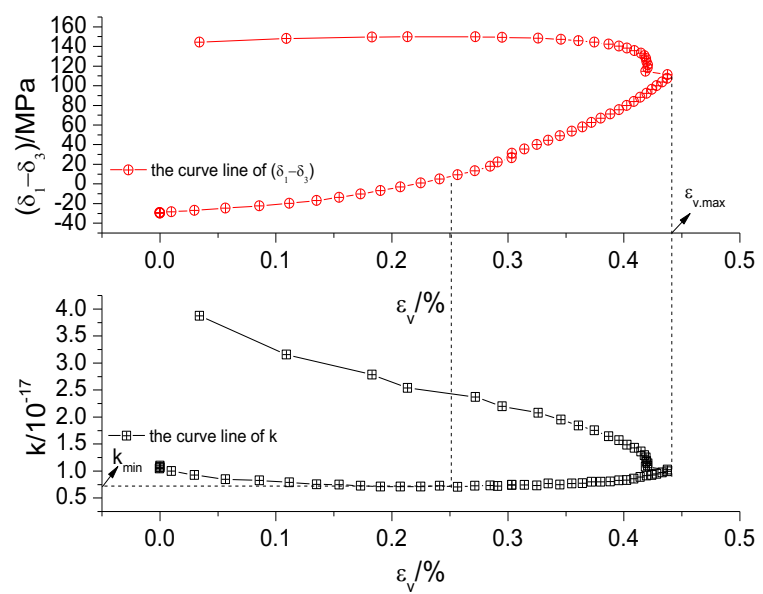

(8) The confining pressure is $30 M P a$ and pore water pressure is $5 \mathrm{MPa}$.

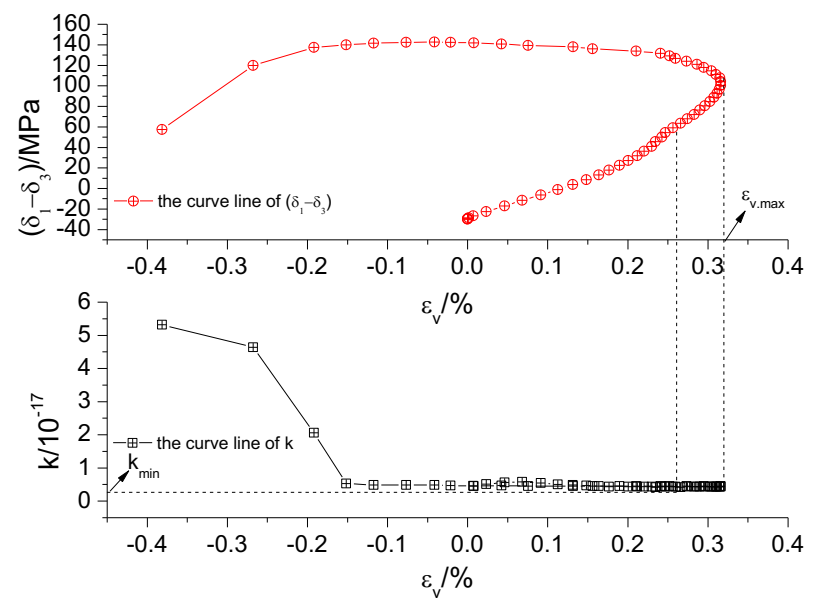

(9) The confining pressure is $30 \mathrm{MPa}$ and pore water pressure is $8 \mathrm{MPa}$.

Fig. 13. Volume strain-deviatoric stress and volume strain-permeability curves under different confining pressures and osmotic pressures

Table 2. Statistical table of maximum volume strain and minimum permeability rate under different confining pressure and water pressure

\begin{tabular}{c|c|c|c}
\hline $\begin{array}{c}\text { Confining } \\
\text { pressure }\end{array}$ & \multicolumn{3}{|c}{ water pressure } \\
\hline $\mathrm{P}=\mathbf{2} M P a$ \\
\hline$M P a$ & $k_{\min } / 10^{-17}$ & $\varepsilon_{v, k_{\min }} / \%$ & $\varepsilon_{v, k_{\max }} / \%$ \\
\hline 10 & 0.775 & 0.125 & 0.217
\end{tabular}


Li-jie Long, Dong-yan Liu, Yan Xiang, Hao Zhang and Shi-hui Liu/

Journal of Engineering Science and Technology Review 13 (4) (2020) 143 - 153

\begin{tabular}{c|c|c|c}
20 & 2.357 & 0.141 & 0.366 \\
30 & 0.174 & -0.065 & 0.306 \\
\hline & \multicolumn{3}{|c}{$\mathrm{P}=5 \mathrm{MPa}$} \\
\hline 10 & 2.598 & 0.113 & 0.164 \\
20 & 1.848 & 0.025 & 0.268 \\
30 & 0.705 & 0.257 & 0.437 \\
\hline & \multicolumn{3}{|c}{$\mathrm{P}=8 M P a$} \\
\hline 10 & 2.04 & 0.149 & 0.217 \\
30 & 2.173 & 0.143 & 0.287 \\
\hline
\end{tabular}

Note: $k_{\min }$ is the minimum permeability, $\varepsilon_{v, k_{\min }}$ is the volume strain corresponding to the minimum permeability, $\varepsilon_{v, k_{\max }}$ is the maximum volume strain value.

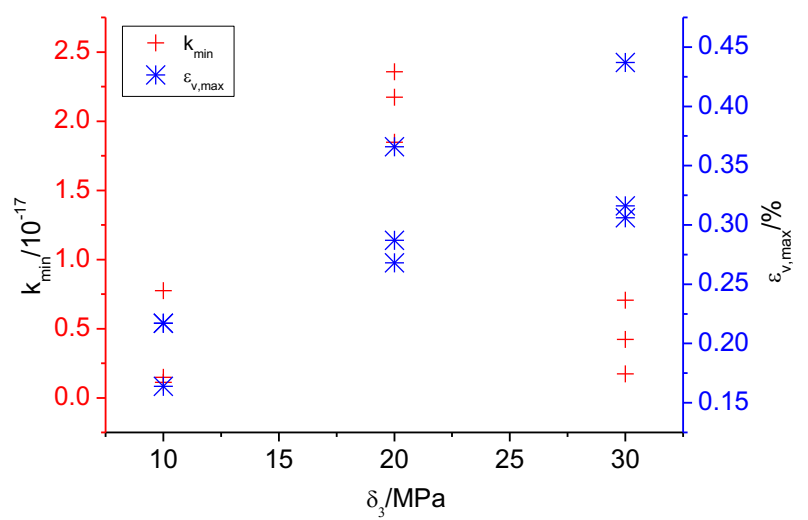

Fig.14. Relationship between maximum volume strain and minimum permeability under different confining pressures

The data in Table 2 are sorted (Figure 14). The result proved that pore water pressure has a slight influence on volume strain. The influence of pore water pressure is ignored to analyze the variation law of confining pressure and maximum volume strain. The average value of maximum volume strain under the same confining pressure is taken for comparison. When the confining pressures are 10,20 , and $30 \mathrm{MPa}$, the average values of $\varepsilon_{v, k_{\max }}$ are 0.199 , 0.307 , and 0.353 , respectively, thereby indicating that the volume strain of rock samples at the maximum compaction point greatly fluctuates with the increase of $35.17 \%$ and $14.98 \%$ when the confining pressure increases from 10 to $30 \mathrm{MPa}$ because the pore water pressure is constant. The mean value of the minimum permeability under the same confining pressure is also taken for comparison. When the confining pressures are 10, 20, and $30 \mathrm{MPa}$, the mean values of the minimum permeability are $1.804,2.126$, and 0.434 , respectively. When the confining pressure is $30 \mathrm{MPa}$, the mean value of the minimum permeability is $24 \%$ of the permeability at $10 \mathrm{MPa}$. The increase in confining pressure restricts the generation and propagation of the internal microcracks in the initial stress stage and inhibits the flow of fluid in the seepage channel, thus reducing the permeability.

$\varepsilon_{v, k_{\min }}$ is the volume strain corresponding to the minimum permeability. The test results demonstrate that the rock sample reaches the maximum compaction in the volume compression stage under the action of eccentric stress, that is, the inflection point in the compression and expansion stage. However, the permeability at the maximum compaction is not the minimum permeability. The minimum permeability of rock sample appears before the inflection point of the volume strain-deviatoric stress curve. The reasons can be summarized as follows:

(1) Rock samples are first loaded by confining pressure in the test. The vertical cracks are first compressed and sealed during the application of confining pressure, thereby decreasing the permeability. The development of internal transverse cracks affects the change of permeability. Although the increase in deviatoric stress first closes the transverse crack and then expands it, the deviatoric stress has a slight effect on permeability in the initial stage. Therefore, the minimum permeability often appears at the transition between the linear elastic and the yield stages, that is, the maximum compression of the transverse crack.

(2) The inflection point of the volume strain-deviatoric stress curve is the maximum compression point of the volume strain. At this point, the volume strain of the sample changes from the compression stage to the volume expansion stage. Under eccentric stress, the rock samples before the inflection point show the compaction and primary formation of internal microcracks. The internal cracks after the inflection point rapidly develop, and the permeability immediately increases.

The axial strain percentage diagram at the minimum permeability is created to analyze the specific stage when the minimum permeability appears in the stress-strain curve. Figure 15 demonstrates that the average percentages of axial strain at the minimum permeability are $23.62 \%, 8.00 \%$, and $17.18 \%$ because the confining pressures are 10,20 , and 30 $M P a$, respectively. When the confining pressure is constant, the osmotic pressure has no significant effect on the law of minimum permeability; when the osmotic pressure is constant, the confining pressure has a significant influence on the law of minimum permeability. When the confining pressure is low, the minimum permeability appears later. When the confining pressure is medium, the minimum permeability appears early. When the confining pressure is high, the minimum permeability appears earlier than the middle and lower confining pressures, which lies between them. In this test, all the minimum permeabilities appeared in the linear elastic stage of the full stress-strain curve. This phenomenon is related to the following: after stress loading, the internal primary pores are compressed and compact, the volume compression degree is large, and the water flow channels, such as pores and fissures between particles, are compressed. The permeability also sharply decreases.

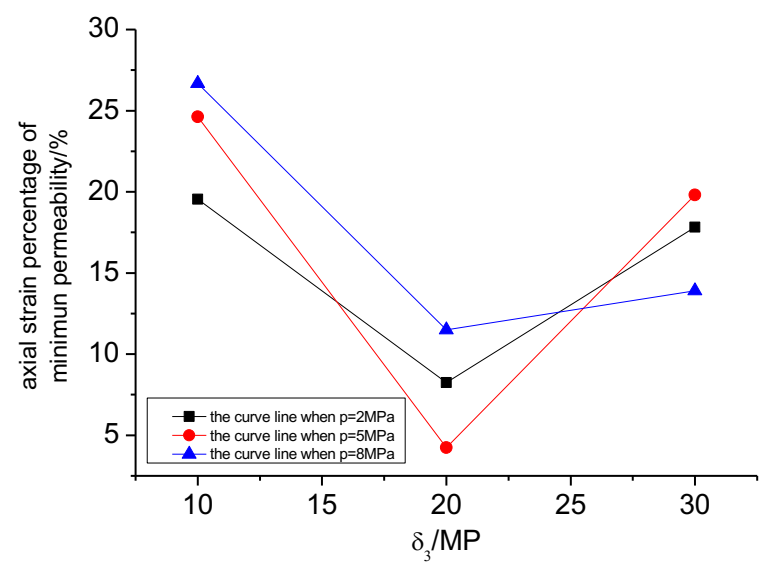

Fig.15. Axial strain percentage of minimum permeability under different confining pressures

\subsubsection{Curve fitting analysis of volume strain and permeability curve}

A close relationship exists between permeability and volume strain of rock. The test data of five rock samples were taken and divided into volume compression and expansion 
Li-jie Long, Dong-yan Liu, Yan Xiang, Hao Zhang and Shi-hui Liu/

Journal of Engineering Science and Technology Review 13 (4) (2020) 143 - 153

sections with the inflection point of volume strain as the boundary. This task was conducted to further explain the relationship between permeability and volume strain of rock samples under seepage-stress coupling. The volume strainpermeability curves under different confining pressure and osmotic pressure were fitted for the second time by quadratic equation:

$$
K=A \varepsilon_{v}^{2}+B \varepsilon_{v}+C
$$

wherein: $A, B$ and $C$ are all fitting parameters, The statistics are shown in Table 3 and table 4 . The correlation coefficients $R^{2}$ are all above $87.8 \%$, and the fitted functional relationship has certain reference value for seepage-stress coupling analysis of rocks.

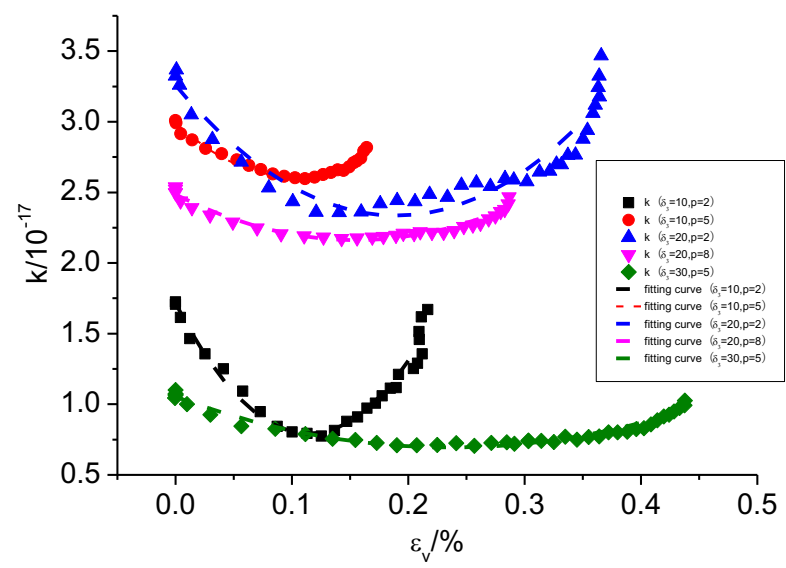

Fig.16. Fitting of volume strain-permeability curve in volume compression stage

Table 3. Parameter table of curve fitting results in volume compression stage

\begin{tabular}{|c|c|c|c|c|c|}
\hline $\begin{array}{c}\text { confining } \\
\text { pressure } \\
/ \mathrm{MPa}\end{array}$ & $\begin{array}{c}\text { osmotic } \\
\text { pressure } \\
\text { / } M P a\end{array}$ & $A$ & $B$ & $C$ & $R^{2}$ \\
\hline 10 & 2 & 70.495 & $16 . \overline{149}$ & 1.717 & 0.949 \\
\hline 10 & 5 & 37.75 & -7.569 & 2.991 & 0.959 \\
\hline 20 & 2 & 25.819 & -9.766 & 3.259 & 0.878 \\
\hline 20 & 8 & 13.395 & -4.157 & 2.485 & 0.938 \\
\hline 30 & 5 & 6.442 & -3.039 & 1.053 & 0.954 \\
\hline
\end{tabular}

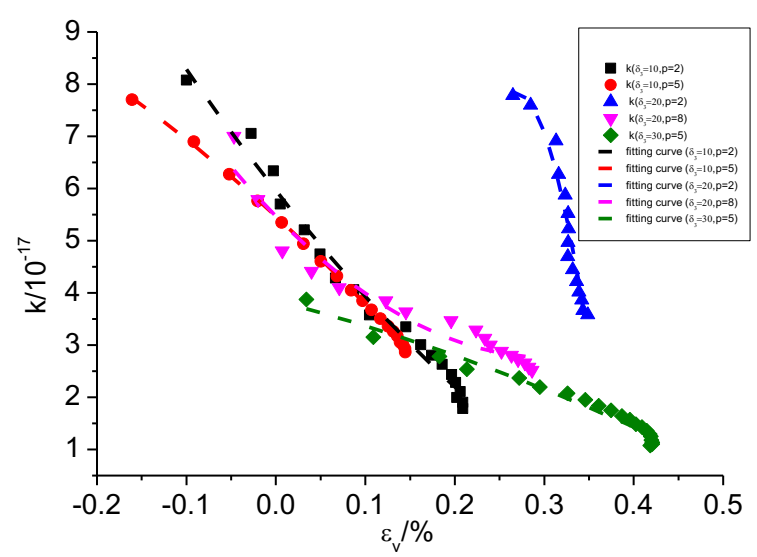

Fig. 17. Fitting of volume strain-permeability curve in volume expansion stage

Table 4. Parameter table of curve fitting results in volume expansion stage

\begin{tabular}{c|c|c|c|c|c}
\hline $\begin{array}{c}\text { confining } \\
\text { pressure } \\
/ \mathrm{MPa}\end{array}$ & $\begin{array}{c}\text { osmotic } \\
\text { pressure } \\
/ \mathrm{MPa}\end{array}$ & $A$ & $B$ & $C$ & $R^{2}$ \\
\hline 10 & 2 & 14.695 & -21.744 & 5.961 & 0.983 \\
10 & 5 & -10.605 & -15.8 & 5.466 & 0.999 \\
20 & 2 & -703.084 & 374.485 & -42.01 & 0.936 \\
20 & 8 & 28.606 & -17.599 & 5.467 & 0.935 \\
30 & 5 & -3.903 & -4.500 & 3.854 & 0.969 \\
\hline
\end{tabular}

\section{Conclusions}

The methods based on the laboratory test and empirical formula fitting analysis were developed to estimate the seepage test of sandstone under seepage-stress coupling action. This initiative was carried out to accurately evaluate the influencing factors of volume strain and permeability of sandstone under seepage-stress action and reveal the coupling law of volume strain and permeability. The following conclusions could be drawn:

(1) Rock is greatly affected by pore water pressure in the initial stage. The pore water pressure is inversely proportional to initial permeability. When the pore water pressure is constant, the initial permeability gradually decreases with the increase in confining pressure.

(2) The volume strain of sandstone increases with the increase in the confining pressure, and the time of expansion deformation lags behind. The inflection point of the volume compression stage to expansion stage also lags behind. However, the change of osmotic pressure has a slight effect on the volume strain of sandstone when the confining pressure is constant.

(3) The expansion starting point appears before the peak stress, and the stress value is smaller than the peak stress. The eccentric stress at the expansion starting point increases with the increase in confining pressure. When the pore water pressure is constant, the confining pressure increases. The volume strain at the expansion generally increases, and the permeability of the samples first increases and then decreases.

(4) The curve of volume strain-deviatoric stress shows that the volume strain of rock sample has undergone two stages of compression and expansion. The maximum volume strain compression increases with the increase in confining pressure. The occurrence point of permeability at the maximum compaction is not the minimum permeability. However, the minimum permeability of the rock sample appears before the inflection point of the volume straindeviatoric stress curve. The test results indicated that the fitting equations of volume strain-permeability curves can efficiently reflect the coupling and evolution law of permeability and volume strain during seepage-stress coupling.

The coupling law of volume strain and permeability is proposed, and the fitting formula of the coupling relationship provides certain reference for the subsequent study. However, the fitted formula is not suitable for all engineering situations due to the lack of field monitoring data. The actual engineering data and this empirical formula will be revised in the future study.

This is an Open Access article distributed under the terms of the Creative Commons Attribution License

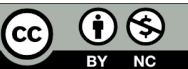




\section{References}

1. Ingraham, M. D., Bauer, S. J., Issen, K. A., Dewers, T. A., "Evolution of permeability and Biot coeffcient at high mean stresses in high porosity sandstone". International Journal of Rock Mechanics and Mining Sciences, 96, 2017, pp. 1-10.

2. Xu, P., Yang, S. Q., "Permeability evolution of sandstone under short-term and long-term triaxial compression". International Journal of Rock Mechanics and Mining Sciences, 85, 2016, pp. 152-164.

3. Yu, J., Li, H., Chen, X., et al., "Triaxial experiment study of associated permeability-deformation of sandstone under hydromechanical coupling". Chinese Journal of Rock Mechanics and Engineering, 32(6), 2013, pp. 1203-1213.

4. Hu, D. W., Zhou, H., et al., "Study of permeability of sandstone in triaxial cyclic stress tests". Rock and Soil Mechanics, 31(9), 2010, pp. 2749-2754.

5. Chen, Y. L., "Permeability evolution of sandstone under multi-field coupling". Journal of Central South University (Science and Technology), 48(9), 2017, pp. 2449-2457.

6. Huo, B. J., Fan Z. L., et al., "Similarity simulation study on permeability of protected coal seam volumetric strain during mining protective coal seam". Coal Science and Technology, 46(7), 2018, pp. 19-25.

7. Zhang, J. W., Song, Z. X., et al., "Experimental study on mechanical behavior and permeability characteristics of sandstone under stressseepage coupling". Chinese Journal of Rock Mechanics and Engineering, 38(7), 2019, pp. 1364-1372.

8. Zhang, C. H., Zhen, X. M., "Strain softening and permeability evolution model of loaded rock and experimental verification". Chinese Journal of Geotechnical Engineering, 38(6), 2016, pp. 1125-1132.

9. Chen, X., Yu, J., Tang, C. A., Li H., Wang, S. Y., "Experimental and numerical investigation of permeability evolution with damage of sandstone under triaxial compression". Rock Mechanics and Rock Engineering, 50, 2017, pp. 1529-1549.

10. Wang, H. L., Xu, W. Y., "Relationship between permeability and strain of sandstone during the process of deformation and failure". Geotechnical and Geological Engineering, 31, 2013, pp. 347-353.
11. Wu, G. J., Chen, W. Z., Rong, C., Jia, S. P., Dai, Y. H. "Elastoplastic damage evolution constitutive model of saturated rock with respect to volumetric strain in rock and its engineering application". Tunnelling and Underground Space Technology, 97, 2020, doi: 10.1016/j.tust.2020.103284

12. Harpalani, S., Chen, G. L., "Influence of gas production induced volumetric strain on permeability of coal". Geotechnical and Geological Engineering, 15, 1997, pp. 303-325.

13. Renard, F., McBeck, J., Cordonnier, B., Zheng, X. J., et al., "Dynamic in situ three-dimensional imaging and digital volume correlation analysisto quantify strain localization and fracture coalescence in sandstone". Pure and Applied Geophysics, 176, 2019, pp. 1083-1115.

14. Farquharson, J. I., Heap, M. J., Baud, P., "Strain - induced permeability increase in volcanic rock". Geophysical Research Letters, 43(22), 2016, pp. 11603-11610.

15. Wei, K. K., Morrow, N. R., Brower, K. R., "Effect of fluid confining pressure and temperature on absolute permeabilities of ow-permeability sandstones". SPE Formation Evaluation, 1(04), 1986. pp. 413-423.

16. Hayes, J. L., Riebe, C. S., Holbrook, W, S., Flinchum, B.A., Hartsough, P.C., "Porosity production in weathered rock Where volumetric strain dominates over chemical mass loss". Science Advances, 5(9), 2019, doi:10.1126/sciadv.aao0834

17. Kim, J. S., Lee, K. S., Cho, W. J., Choi, H. J., Cho, G. C., “A comparative evaluation of stress-strain and acoustic emission methods for quantitative damage assessments of brittle rock". Rock Mechanics and Rock Engineering, 48, 2015. pp. 495-508.

18. Shalev, E., Kurzon, I., Doan, M. L., Lyakhovsky, V., "Water-level oscillations caused by volumetric and deviatoricdynamic strains". Geophysical Journal International, 204, 2015, pp. 841-851.

19. Nermoen, A., Korsnes, R. I., Hiorth, A., Madland M.V., "Porosity and permeability development in compacting chalks during flooding of nonequilibrium brines: Insights from long-term experiment". Journal of Geophysical Research: Solid Earth, 120, 2015, pp. 2935-2960

20. Alkan, H., Cinar, Y., Pusch, G., "Rock salt dilatancy boundary from combined acoustic emission and triaxial compression tests". International Journal of Rock Mechanics and Mining Sciences, 44, 2007, pp. 108-119. 